\title{
Evaluation of Mechanical Properties of Rice Husk-Fly Ash-Epoxy Hybrid Composites
}

\author{
Antaryami Mishra ${ }^{1}$, Deepanjali Padhee ${ }^{2}$ \\ ${ }^{I}$ Professor, Department of Mechanical Engineering, Indira Gandhi Institute of Technology, Saranga-759146, \\ Odisha, India \\ ${ }^{2}$ M.Tech Scholar, Indira Gandhi Institute of Technology, Sarang-759146, Odisha, India
}

\begin{abstract}
An attempt has been made in this investigation to develop natural fibers reinforced polymer composites using rice husk and fly ash as reinforcements. The content of rice husk is varied $(10,15$ and 20 weight percentages) whereas the fly ash percentage is kept constant at $5 \%$ in epoxy matrix. Composites have been fabricated using hand layup technique using a suitable die developed in house. All the samples have been tested in Universal Testing Machine as per standard for tensile strength and flexural strength. The hardness and water absorption tests were also carried out. It is observed that composite with $10 \%$ rice husk is having highest tensile strength of $33 \mathrm{MPa}$. Similarly the flexure modulus for $10 \%$ rice husk composite was $4881 \mathrm{MPa}$. The impact strength of composite with $20 \%$ rice husk was highest. The hardness test showed that composite of $20 \%$ rice husk was highest. The water absorption test reveals that composite with $10 \%$ rice husk is the best. It is recommended that composite with $10 \%$ rice husk and $5 \%$ fly ash with epoxy matrix will be suitable for structural applications. The composite with 15 or $20 \%$ rice husk may not be used for such purposes. Composite with 15 and $20 \%$ rice husk may be used for making parts of automobiles. But these will not be suitable to work in moist environment. However composite with $10 \%$ rice husk will be suitable for structural applications like packaging, interior decorations, body of washing machines and domestic appliances etc.
\end{abstract}

Keywords: Rice Husk-Fly Ash-Epoxy Hybrid Composites, tensile, hardness, flexure, impact, water absorption tests

\section{Introduction}

Lot of research is going on in the field of material science to develop environment friendly material due to increasing concern about environment and depleting conventional materials. Under circumstances natural fibers and bio waste have become interesting materials to be used as reinforcement in polymer matrix to develop green composites. Application of high-performance composites using natural fibers is increasing in various engineering fields. Composite materials comprising one or more phase(s) belonging to natural or biological origin are called green or bio-composite. During the last decade there has been a renewed interest in the natural fibres as substitute for glass, motivated by potential advantage of weight saving, lower raw material price, and thermal recycling or the ecological advantages of using resources which are renewable. The composites produced today with the incorporation of natural fibres as reinforcements in polymeric matrix are used for boat hulls, surfboards, sporting goods, swimming pool linings, building panels and car bodies. This not only reduces the cost but also save from environmental pollution and waste otherwise thrown in the open. These composites are also used in panels for partition and false ceiling, partition boards, wall, floor, window and door frames, roof tiles, mobile or pre-fabricated buildings which can be used in times of natural calamities such as floods, cyclones, earthquakes, etc. Keeping this in view it has been thought proper to develop hybrid composites of rice husk, fly ash and epoxy where the fly ash content is kept constant and rice husk percentage is varied as reinforcements..

\section{Literature Review}

An attempt has been made here to know the direction of research in the field of natural fibre reinforced polymer composites using fly ash and rice husk as reinforcements. Therefore review of literature has been carried out over last decade. Saxena et al. [1] investigated industrial waste reinforced polymer composites as a potential wood substitute material. Plant fiber along with industrial waste (fly ash and red mud) were used for synthesizing the composite materials. Properties such as physical and mechanical, resistance to abrasive wear, weathering and fire etc. were studied. It was observed that polymer - natural fiber-industrial (inorganic) waste composites attain far superior mechanical properties and resistance to abrasive wear, fire, water absorption, weathering, and chemical attack, as compared to their conventional counterparts such as wood, medium density fibre (MDF) boards, particle board, etc. Harish et al. [2] evaluated the mechanical properties of natural fibre coir composites. Coir instead of artificial fibre such as glass, carbon etc. was used to develop composites and each fibre was about 0.01 to 0.04 in. $(0.03$ to $0.1 \mathrm{~cm})$ long and 12 to $24 \mu \mathrm{m}$ in diameter. Composites were prepared by 
hand layup technique with matrix as epoxy. After testing it was found that the tensile strength, flexural strength and impact strength of composites have substantially increased. Singla and Chawla [3] investigated the mechanical strength of epoxy resin fly ash composite. Composite preparation was done by taking different weight percentage of fly ash and resin. Material was subjected to compression and impact test by taking different weight percentage of fly ash. It was observed that the compressive strength of the composite increased with increase of fly ash percentage. The effect of particle size and volume fraction on tensile properties of flyash/polyurea composites was carried out by Qiao et al.[4]. A one-step method was chosen to fabricate pure polyurea and the polyurea matrix for the composites based on Isonate 2143L (diisocyanate) and Versalink P1000 (diamine). Scanning electron microscopy was used to observe the fracture surfaces of the composites. The tensile properties of the pure polyurea and fly ash/polyurea (FA/PU) composites were tested using an Instron load frame with a $1 \mathrm{kN}$ Interface model 1500ASK-200 load cell. Results showed that fly ash particles were distributed homogeneously in the polyurea matrix and all of the composites displayed rubber-like tensile behavior similar to that of pure polyurea. The tensile strength of the composites was influenced by both the fly ash size and the volume fraction. Compared to the largest particle size or the highest volume fraction, an increase in tensile strength was achieved by reducing particle size and/or volume fraction. The strain at break of the composites also increased by using fine particles. Sayfri et al.[5]investigated effect of rice husk surface modification by LENR(Liquid Epoxidized Natural Rubber ) the on mechanical properties of nr/hdpe reinforced rice husk composite. Surface modification of rice husk $(\mathrm{RH})$ with alkali pre-treatment $(\mathrm{NaOH}$ solution $5 \%$ w/v) was carried out at the initial state to investigate the effect of surface treatment of fibre on the surface interaction between fibre and rubber. Further modification of RH surfaces after alkali treatment was using LENR coating at three concentrations, $5 \%, 10 \%$, and $20 \%$ wt LENR solution in toluene. It was found that $10 \%$ wt LENR solution gave the optimum interaction between fibre and rubber. Result showed that pre-treatment of RH treated with 5\% $\mathrm{NaOH}$ followed by treatment with $10 \%$ LENR solution given the maximum interaction between fibre and matrix that gave rise to better mechanical properties of the composites. Rout and Satapathy [6] studied the mechanical and tribo-performance of rice-husk filled glass-epoxy hybrid composites. The results indicate that impact velocity, filler content, impingement angle and erodent size influence the wear rate significantly. This study reveals that hardness, tensile modulus, impact energy and erosion resistance of these new class hybrid composites are improving with filler addition while a steady decline in tensile and flexural properties are observed. Shubham and Tiwari [7] investigated effect of fly ash concentration and surface modification of fiber reinforced epoxy composite. It was shown that damping capability and thermal stability were improved with low concentration of fly ash. .It was observed that silanization of fly ash had improved the tensile strength and toughness. SEM analysis showed that surface modification of fly ash with coupling agent enhanced their bonding with polymer resin which resulted in lower damping capability and improved strength and toughness. Raghavendra et al. [8] investigated mechanical properties of fly ash filler in natural fiber- hybrid epoxy composites. The laminates of 4 piles were prepared by using hand lay-up technique.. One group of glass laminate was also fabricated for comparison purpose. Specimen preparation and testing was carried out as per ASTM standards. Due to incorporation of fly ash fillers in to the jute composites there is $10 \%$ of strength increment in tensile and $20 \%$ in flexural. He found that by incorporation of bio and industrial waste in to the polymer material the mechanical properties almost enhanced to a greater extent.The $10 \%$ fly ash filler reinforced composites give almost 55\% of the glass fiber composite strength. Arpitha et al. [9] considered epoxy, Sisal fiber, glass fiber, silicon carbide as filler materials in polymer respectively to make composites. Experiments were conducted by varying weight fractions of $\mathrm{SiC}(3,6,9 \%)$ while keeping all other parameters constant. It was observed that Sisal/Glass composite samples possess good tensile strength and impact strength. It was also found that sisal/glass with $3 \%$ of silicon carbide filler shows good flexural strength compared to other composites. Islam et al.[10] studied physio-mechanical properties of rice husk ash polyester resin composite. The rice husk ash/polyester resin composites were prepared by compression molding method and their physical and mechanical properties were studied. it was observed that the bulk density of rice husk ash/polyester composites decreased very slowly with an increase in the amount of rice husk ash content. Vishnu and Manavendra [11] investigated the thermal properties of fly ash reinforced epoxy composite. The investigation has focused on the maximum utilization of abundantly available industrial waste fly ash in a useful manner. The thermal properties of the composites like Thermal conductivity, Specific heat capacity, Linear coefficient of Thermal expansion and Thermal diffusivity were experimentally determined in the engineering laboratory.It was observed that the incorporation of fly ash particles results in decrease in the thermal conductivity compared to that of pure epoxy thereby improves its thermal insulation capability and exhibit higher specific heat carrying capacity than composite without fly ash because higher fly ash content in composite higher will be the heat carrying capacity of the composite. Mishra [12] investigated the mechanical characteristics of chicken feather-teak wood dust filled epoxy composites. Composites of teak wood dust (450 $\mu \mathrm{m}$ size) in 10,15 and 20 percentages of weight mixed with epoxy along with $5 \%$ of chopped chicken feather have been prepared by hand lay up technique. The tensile strength was tested by universal testing machine. The 
water absorption tests in 24 hours was done. The results show the gain in weight is very little and negligible for all the composites So the composites can perform very well in moist atmosphere.

\section{Scope}

The following objectives have been set for the present investigation.

1. To develop hybrid composites of rice husk, fly ash and epoxy composites by varying the percentages of rice husk.

2. Fly ash content is kept constant at $5 \%$ of the weight and rice husk at 10,15 and 20 weight percentages.

3. Composite will be prepared by hand layup technique in the form of lamina.

4. Test specimens as per standards will be prepared for tensile, flexural strength, hardness and water absorption tests etc.

5. The results after testing will be analyzed and the best out of the above specimen will be chosen for specific engineering applications.

\section{Theoretical Investigations}

The composite is usually prepared based on calculation of weight fractions or volume fractions of matrix or filler material. Since random distribution of filler material has been considered various properties of the composite are found out following rule of mixtures as mentioned below.

Weight fraction of the reinforcement: $\mathrm{W}_{\mathrm{r}}=\mathrm{W}_{\mathrm{r}} /\left(\mathrm{W}_{\mathrm{r}}+\mathrm{W}_{\mathrm{m}}+\mathrm{W}_{\mathrm{f}}\right) * 100$,

Weight fraction of the matrix: $\mathrm{w}_{\mathrm{m}}=\mathrm{W}_{\mathrm{m}} /\left(\mathrm{W}_{\mathrm{r}}+\mathrm{W}_{\mathrm{m}}+\mathrm{W}_{\mathrm{f}}\right) * 100$

Weight fraction of the filler: $\mathrm{W}_{\mathrm{f}}=\mathrm{W}_{\mathrm{f}} /\left(\mathrm{W}_{\mathrm{r}}+\mathrm{W}_{\mathrm{m}}+\mathrm{W}_{\mathrm{f}}\right) * 100$

Where $\mathrm{W}_{\mathrm{r}}=$ Weight of reinforcement (rice husk), $\mathrm{W}_{\mathrm{m}}=$ Weight of matrix (epoxy) and $\mathrm{W}_{\mathrm{f}}=$ Weight of filler.(Fly ash)

Weight of the composite $=\mathrm{W}_{\mathrm{c}}=\mathrm{W}_{\mathrm{r}}+\mathrm{W}_{\mathrm{m}}+\mathrm{W}_{\mathrm{f}}$

Further as per rule of mixtures, the density of the composite is obtained by

$$
\rho_{\mathrm{c}}=\rho_{\mathrm{m}} \mathrm{v}_{\mathrm{m}}+\rho_{\mathrm{r}} \mathrm{v}_{\mathrm{r}}+\rho_{\mathrm{f}} \mathrm{v}_{\mathrm{f}}
$$

where $\rho_{\mathrm{c}}=$ Density of the composite, $\rho_{\mathrm{m}}=$ Density of the matrix, $\rho_{\mathrm{r}}=$ Density of the reinforcement and $\rho_{\mathrm{f}}=$ Density of the filler

$\mathrm{v}_{\mathrm{m}}=$ Volume fraction of the matrix, $\mathrm{v}_{\mathrm{r}}=$ Volume fraction of the reinforcement and $\mathrm{v}_{\mathrm{f}}=$ Volume fraction of filler Here $\mathrm{v}_{\mathrm{m}}=\mathrm{V}_{\mathrm{m}} /\left(\mathrm{V}_{\mathrm{m}}+\mathrm{V}_{\mathrm{r}}+\mathrm{V}_{\mathrm{f}}+\mathrm{V}_{\mathrm{v}}\right) * 100, \quad \mathrm{~V}_{\mathrm{r}}=\mathrm{V}_{\mathrm{r}} /\left(\mathrm{V}_{\mathrm{m}}+\mathrm{V}_{\mathrm{r}}+\mathrm{V}_{\mathrm{f}}+\mathrm{V}_{\mathrm{v}}\right) * 100$ and

Volume of the composite $=\mathrm{V}_{\mathrm{c}}=\mathrm{V}_{\mathrm{m}}+\mathrm{V}_{\mathrm{r}}+\mathrm{V}_{\mathrm{f}}+\mathrm{V}_{\mathrm{v}}$

Where $\mathrm{V}_{\mathrm{m}}=$ Volume of the matrix, $\mathrm{V}_{\mathrm{r}}=$ Volume of the reinforcement, $\mathrm{V}_{\mathrm{f}}=$ Volume of filler and $\mathrm{V}_{\mathrm{v}}=$ Volume of voids ( not considered here)

Assuming modulus reinforcing efficiency as unity and as per rule of mixtures: Modulus of elasticity of the composite

$$
\mathrm{E}_{\mathrm{c}}=\mathrm{E}_{\mathrm{m}} \mathrm{v}_{\mathrm{m}}+\mathrm{E}_{\mathrm{r}} \mathrm{v}_{\mathrm{r}}+\mathrm{E}_{\mathrm{f}} \mathrm{v}_{\mathrm{f}}
$$

Where $E_{\mathrm{r}}=$ Modulus of elasticity of reinforcement, $\mathrm{E}_{\mathrm{m}}=$ Modulus of elasticity of Matrix and $\mathrm{E}_{\mathrm{f}}=$ Moduus of elasticity of filler.

Strength of the composite

$$
\sigma_{\mathrm{c}}=\sigma_{\mathrm{m}} \mathrm{v}_{\mathrm{m}}+\sigma_{\mathrm{r}} \mathrm{v}_{\mathrm{r}}+\sigma_{\mathrm{f}} \mathrm{v}_{\mathrm{f}}
$$

Where $\sigma_{\mathrm{r}}=$ strength of the reinforcement, $\sigma_{\mathrm{m}}=$ Strength of the matrix and $\sigma_{\mathrm{f}}=$ Strength of Filler.

Properties of individual constituents are given in Table 1,2 and 3.

Table 1 Properties of epoxy

\begin{tabular}{|l|l|}
\hline \multicolumn{1}{|c|}{ Properties } & Value \\
\hline Density (gm/cc) & 1.2 \\
\hline Elastic modulus (GPa) & 20 \\
\hline $\begin{array}{l}\text { Tensile strength } \\
\text { (MPa) }\end{array}$ & 75 \\
\hline
\end{tabular}

Table 2 Properties of rice husk

\begin{tabular}{|l|l|}
\hline \multicolumn{1}{|c|}{ Properties } & Value \\
\hline Density $(\mathrm{gm} / \mathrm{cc})$ & 1.0 \\
\hline Elastic modulus $(\mathrm{GPa})$ & 5.0 \\
\hline Tensile strength $(\mathrm{MPa})$ & 180 \\
\hline
\end{tabular}

Table 3 Properties of fly ash

\begin{tabular}{|l|l|}
\hline \multicolumn{1}{|c|}{ Properties } & Value \\
\hline Density (gm/cc) & 1.53 \\
\hline Elastic modulus $(\mathrm{GPa})$ & 2.3 \\
\hline Compressive strength $(\mathrm{MPa})$ & 17 \\
\hline
\end{tabular}

Using Eqns 1,2 and 3 the properties of the composites have been found out as in Table 4 . 


Table.4 Properties of Composite
\begin{tabular}{|l|l|l|l|}
\hline Composites & Density (gm/cc) & $\begin{array}{l}\text { Elastic modulus } \\
(\mathrm{GPa})\end{array}$ & $\begin{array}{l}\text { Tensile strength } \\
(\mathrm{MPa})\end{array}$ \\
\hline Specimen-A & 1.1965 & 17.615 & 80.9 \\
\hline Specimen-B & 1.1865 & 17.115 & 95.15 \\
\hline Specimen-C & 1.1765 & 16.365 & 100.4 \\
\hline
\end{tabular}

Specimen -A - $10 \%$ Rice husk composite

Specimen-B - $15 \%$ Rice husk composite

Specimen-C - $20 \%$ rice husk composite

\section{Experimental Work}

\section{Materials}

Fly ash sample used in this study was collected from National Thermal Power Corporation Ltd, Talcher Thermal. (Fig.1). Upon collection, the fly ash was first dehydrated in the oven at $105^{\circ} \mathrm{C}$. The mesh size of the fly ash has been measured in scanning electron microscope and average size was found to be $100 \mu \mathrm{m}$ (Fig.2).

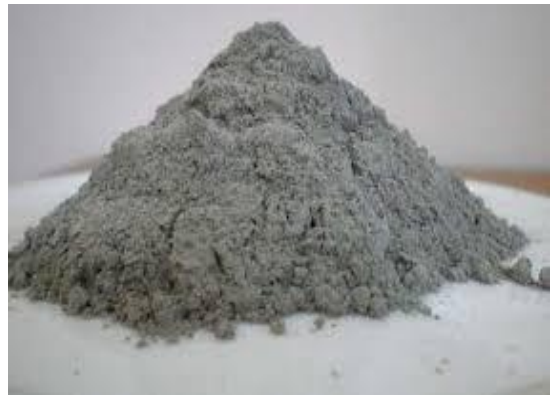

Fig. 1.Fly Ash sample

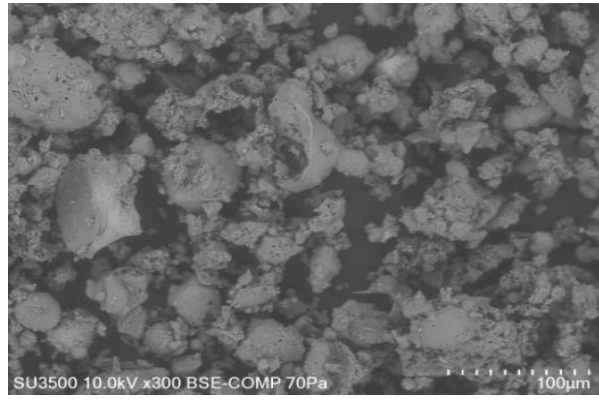

Fig..2. SEM of fly Ash (size- $100 \mu \mathrm{m})$

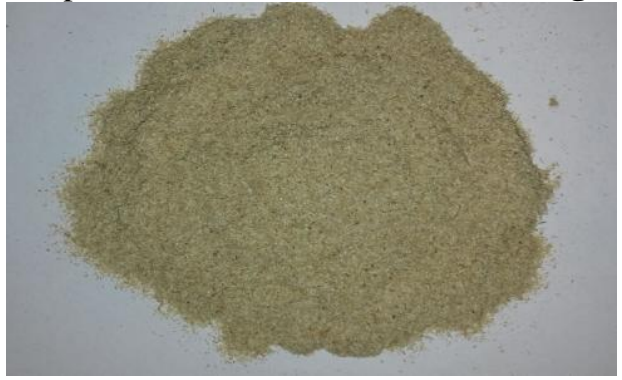

Fig. 3 Rice husk sample

Rice husk sample (Fig.3) was collected from the rice mill, Sambalpur, Odisha. For removing the moisture content it was dried up in an oven at $100^{\circ} \mathrm{C}$. The size of rice husk was found to be $426 \mu \mathrm{m}$ measured through a sieve shaker. Epoxy CY230 and Hardner HY951 were collected from Hindustan Ciba Geigy Ltd., Kolkata, India

\section{Composite Preparation}

A wooden mould of dimension $(100 \times 100 \times 10) \mathrm{mm}^{3}$ was used for casting the composite sheet (Fig.4). The samples were manufactured with different weight fractions of rice husk and fly ash. With different weight fraction of rice husk $(10,15$ and $20 \%)$, fly ash (5\%-constant ) epoxy and hardener was thoroughly mixed with gentle stirring to minimize air entrapment. The epoxy and hardener were mixed in 10:1 ratio. Then by using hand layup technique, the mixture was poured into the mold. For quick and easy removal of composite sheets, mold release agent (silicone spray)was applied at the inner surface of the mould. Care was taken to avoid formation of air bubbles. The mold was allowed to cure at room temperature for $24 \mathrm{hrs}$. After $24 \mathrm{hrs}$ the samples were taken out of the mould (Fig.5 a,b,c), cut into different sizes as per standard for further experimentation.

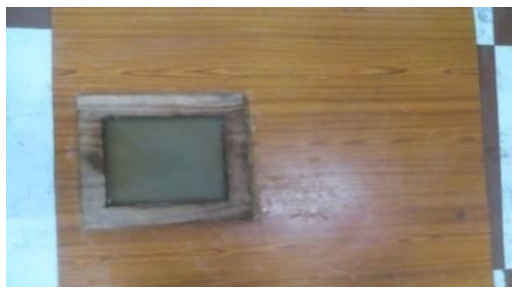

Fig.4. Wooden mould and cast specimen 


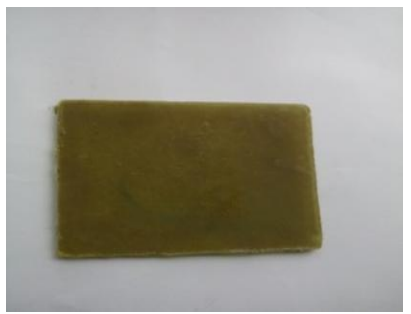

(a)

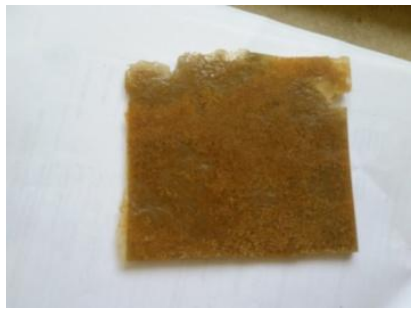

(b)

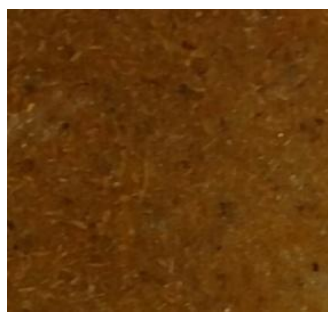

(c)

Fig. 5 a,b,c. Composite Lamina with $10 \%, 15 \%$ \& 20\% rice husk respectively

\section{Test procedures}

Tensile test

The coupon test samples for tensile test (Fig.6) are cut from the lamina according to reference standard of ASTM as shown in Fig.6 and actual dimensions are also given in Table 5. The tensile test was done according to ASTM standard (D-638) in Universal Testing Machine, UK make (Fig.7) The specification of the machine is given in Table 6.

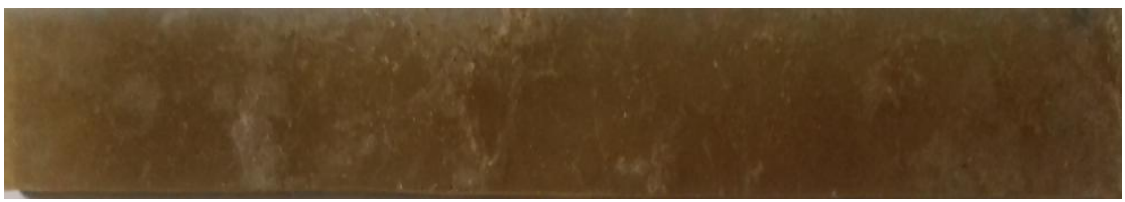

Fig..6 Coupon test sample

Table 5.Actual dimensions of the test specimens

\begin{tabular}{|c|c|c|c|}
\hline Specimen & Length $(\mathrm{mm})$ & Width $(\mathrm{mm})$ & Thickness $(\mathrm{mm})$ \\
\hline A & 200 & 24 & 8.2 \\
\hline B & 200 & 24 & 3 \\
\hline C & 200 & 24 & 2.5 \\
\hline
\end{tabular}

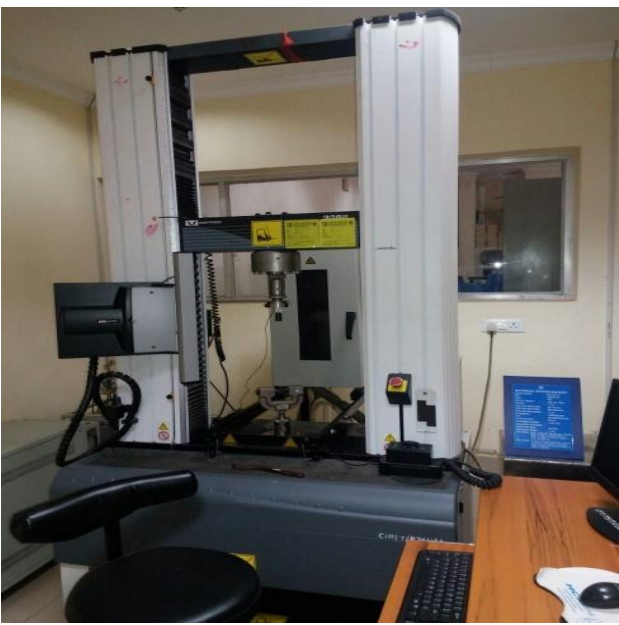

Fig.7.UTM for tensile test

Table 6 Specification of UTM

\begin{tabular}{|c|c|c|}
\hline Machine Capacity & $\mathrm{kN}$ & 250 \\
\hline Machine Capacity & tons & 25 \\
\hline Maximum Testing Speed & $\mathrm{mm} / \mathrm{min}$ & 300 \\
\hline Minimum Testing Speed & $\mathrm{mm} / \mathrm{min}$ & 0.1 \\
\hline Jog Speed & $\mathrm{mm} / \mathrm{min}$ & up to 400 \\
\hline Speed Accuracy & $\mathrm{mm} / \mathrm{min}$ & 0.1 \\
\hline Positioning Accuracy & $\mathrm{mm}$ & 0.01 \\
\hline Horizontal Clearance & $\mathrm{mm}$ & 600 \\
\hline Crosshead Travel Excluding Grips & $\mathrm{mm}$ & 1320 \\
\hline Crosshead Travel with Wedge Grips \\
Installed & $\mathrm{mm}$ & 800 \\
\hline Overall Height & $\mathrm{mm}$ & 2460 \\
\hline Overall Width & $\mathrm{mm}$ & 1300 \\
\hline Overall Depth & $\mathrm{mm}$ & 670 \\
\hline Weight(approx.) & $\mathrm{kgs}$ & 880 \\
\hline
\end{tabular}




\section{Flexural Modulus test}

The flexural modulus test was done according to ASTM standard (D-790) in the same UTM with three point bending.

\section{Impact strength}

The Izod impact strength test was done according to ASTM standard (D-256). The machine has benn shown in Fig.8.

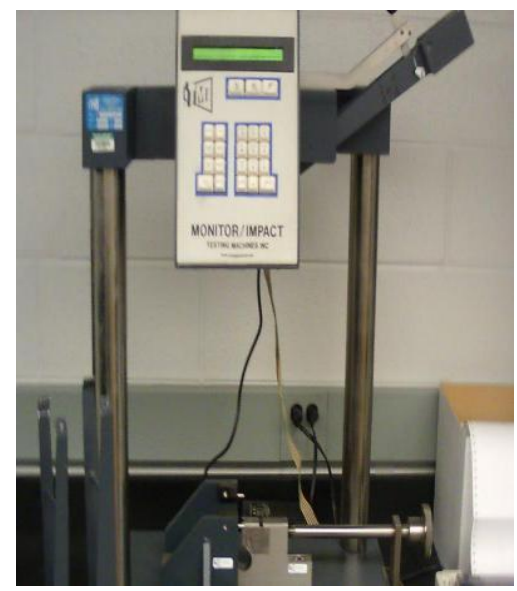

Fig. 8 Izod impact test

\section{Water absorption}

The water absorption test as per standard ASTM- D570 was conducted. The specimen A was of 50x50x $8 \mathrm{~mm}$ and specimen $\mathrm{B}$ and $\mathrm{C}$ were of $50 \times 50 \times 3 \mathrm{~mm}$ size (Fig. 8). The test was conducted for $24 \mathrm{hrs}$ and $72 \mathrm{hrs}$ respectively for all the specimens. The dry weight and final weights were measured through an electronic balance of three decimal accuracy to ontain the gain in weight.

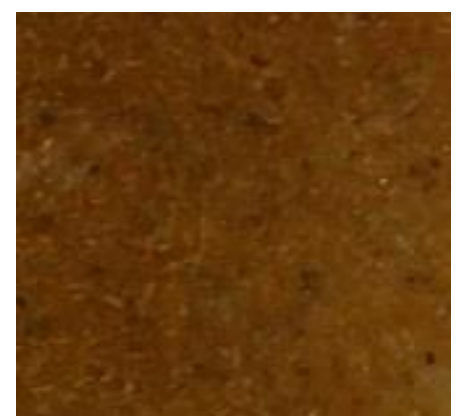

Fig.8. Water absorption test sample

\section{Hardness test}

The Rockwell hardness test was done according to ASTM standard (D-785) in a Rockwell Hardness Tester (Fig.9).

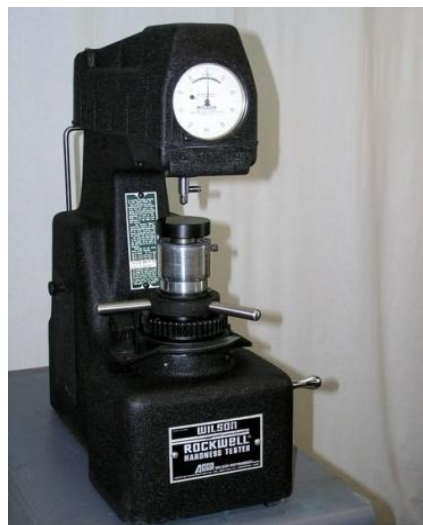

Fig. 9 Rockwell hardness tester 


\section{Results And Discussion}

The results of tensile tests for three different specimens have been plotted in Fig. 10,11 and 12 for 10.15 and $20 \%$ rice husk composites respectively. These results are interpreted in Table 7.

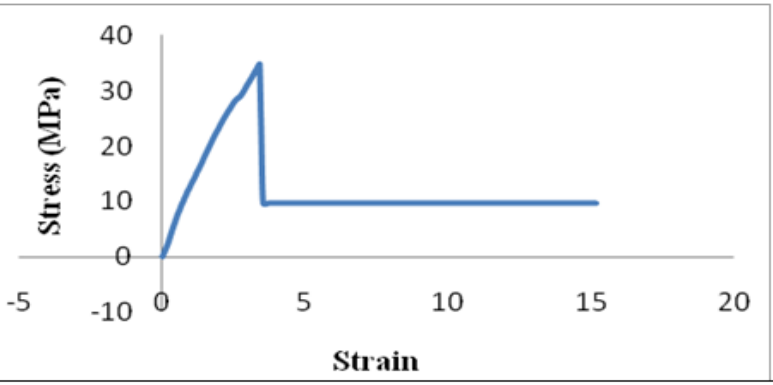

Fig. 10 Tensile test of composite having $10 \%$ rice husk

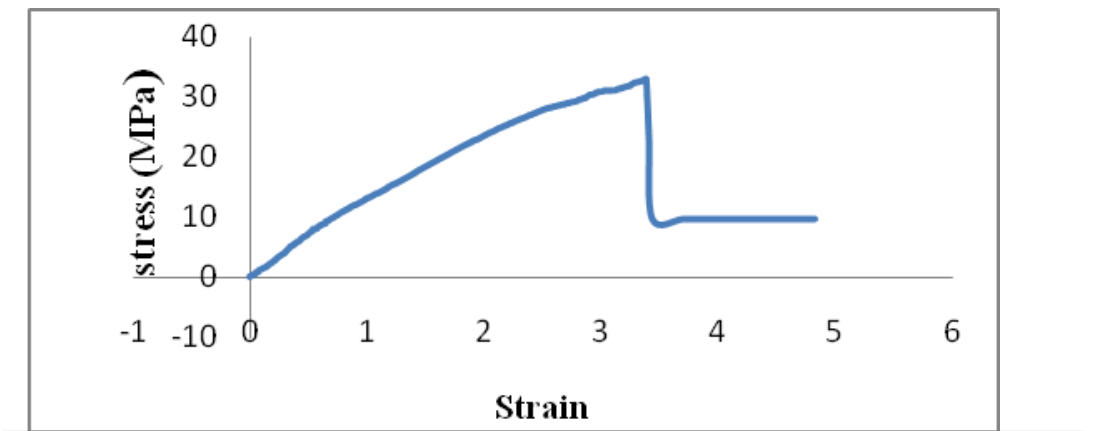

Fig. 11 Tensile test of composite having $15 \%$ rice husk

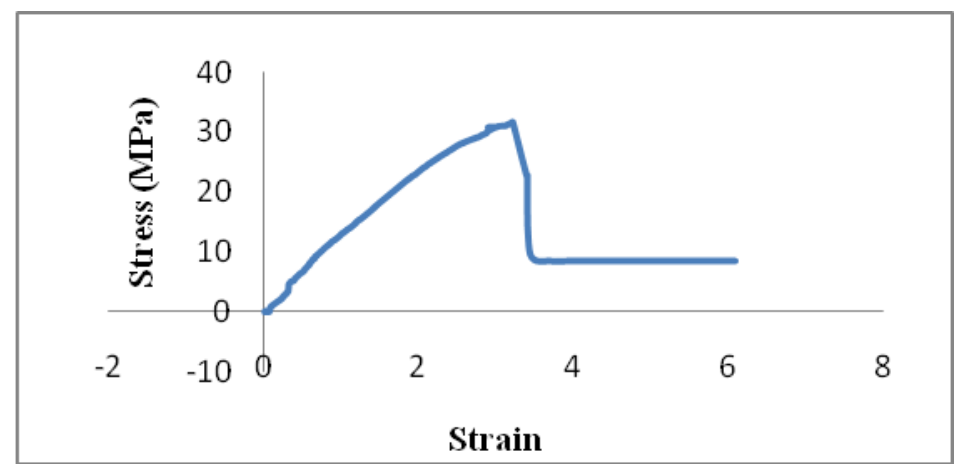

Fig. 12 Tensile test of composite having 20\% rice husk

Table 7 Results of tensile test

\begin{tabular}{|c|l|l|l|l|l|l|l|}
\hline Specimen & $\begin{array}{l}\text { Gage length } \\
(\mathrm{mm})\end{array}$ & $\begin{array}{l}\text { Maximum load } \\
(\mathrm{kN})\end{array}$ & $\begin{array}{l}\text { Tensile strength } \\
(\mathrm{MPa})\end{array}$ & $\begin{array}{l}\text { Breaking(kn/ } \\
\mathrm{m})\end{array}$ & $\begin{array}{l}\text { Load at break } \\
(\mathrm{kN})\end{array}$ & $\begin{array}{l}\text { Strength at } \\
\text { break(}(\mathrm{MPa})\end{array}$ & $\begin{array}{l}\text { Elastic modulus } \\
(\mathrm{GPa})\end{array}$ \\
\hline A & 85 & 6.840 & 35 & 0.28 & 1.900 & 10 \\
\hline B & 86 & 6.810 & 33 & 0.25 & 1.756 & 9.5 \\
\hline C & 85 & 6.650 & 32 & 0.22 & 1.650 & 1.06 & 9.3 \\
\hline
\end{tabular}

The plot of flexural stress and flexural strain for three types of composites is indicated in Fig. 12.
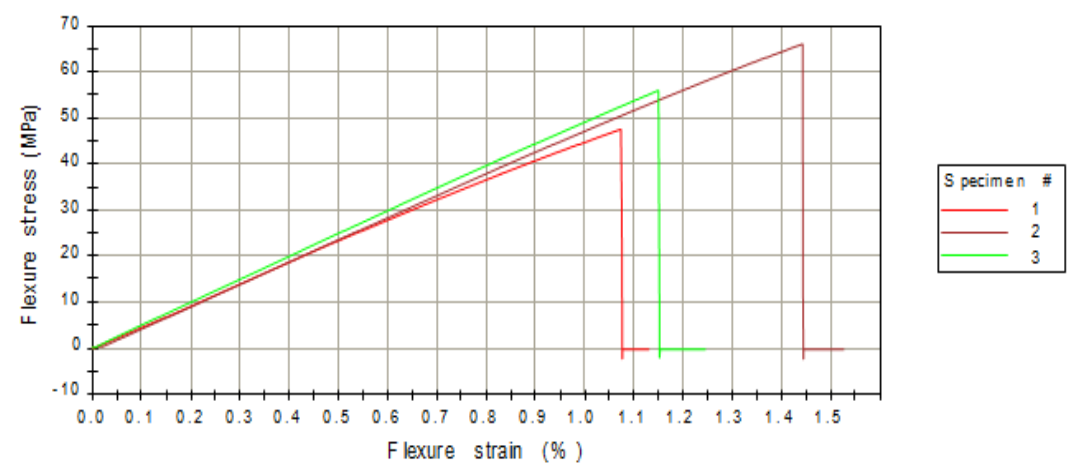

Fig.13. Stress-Strain curve for flexure test 
The value of flexural modulus obtained are 4881.75MPa, 2846.70 MPa and 2884.80 MPa for 10,15 and $20 \%$ rice husk composites respectively. The results obtained from impact and hardness tests are indicated in Table 8 .

Table 8 Impact strength and hardness

\begin{tabular}{|l|l|l|}
\hline Specimen & Impact strength $(\mathrm{J} / \mathrm{m})$ & Hardness $(\mathrm{RC})$ \\
\hline A & 8.91 & 65.12 \\
\hline B & 16.07 & 60.8 \\
\hline C & 20.85 & 70.2 \\
\hline
\end{tabular}

The water absorption test results after soaking for $24 \mathrm{hrs}$ and $72 \mathrm{hrs}$ are given in Table 9 and 10 .

Table 9.Results of water absorption test after 24 hrs soaking

\begin{tabular}{|c|l|l|c|}
\hline Sl.No & $\begin{array}{l}\text { Wt. of dry composite } \\
\text { (Kg.) }\end{array}$ & $\begin{array}{l}\text { Wt. of composite after water } \\
\text { absorbed } \\
\text { (Kg.) }\end{array}$ & $\begin{array}{c}\text { Gain in weight } \\
(\%)\end{array}$ \\
\hline A & 0.040 & 0.041 & 2.5 \\
\hline B & 0.020 & 0.022 & 10 \\
\hline C & 0.015 & 0.017 & 13.33 \\
\hline
\end{tabular}

Table 10. Water absorption test for $72 \mathrm{hrs}$

\begin{tabular}{|c|c|c|c|}
\hline SL NO. & $\begin{array}{l}\text { Wt. of dry composite } \\
\text { (Kg.) }\end{array}$ & $\begin{array}{l}\text { Wt. of composite after } \\
\text { water absorbed } \\
\text { (Kg.) }\end{array}$ & Gain in weight (\%) \\
\hline A & 0.040 & 0.042 & 5 \\
\hline B & 0.020 & 0.023 & 15 \\
\hline C & 0.015 & 0.018 & 20 \\
\hline
\end{tabular}

From the results obtained as above it is now observed that the composite having $10 \%$ rice husk is having maximum tensile strength i.e $35 \mathrm{MPa}$ and flexural modulus of $4881.75 \mathrm{MPa}$. Hardness of this composite is also moderate having $65.12 \mathrm{RC}$. But for this material the impact strength is low. As far as water absorption capacity is concerned the specimen sample of $10 \%$ rice husk exhibited excellent property and suitable to work in moist environment. However the sample with $20 \%$ rice husk is having hardness of $70.2 \mathrm{RC}$, highest impact strength, low flexural and tensile strengths. This composite may not be recommended for use in aquatic environment. Thus where hardness and impact properties are required the sample $\mathrm{C}$ may be used or sample B.

\section{Conclusions}

After developing natural fibre reinforced composites prepared out of waste like fly ash and rice husk it is observed that composite with $10 \%$ rice husk and $5 \%$ fly ash with epoxy matrix will be suitable for structural applications. The composite with 15 or $20 \%$ rice husk may not be used for such purposes. Now a days the automobile industry is in search of light weight materials to reduce the overall weight of the vehicle. Composite with 15 and $20 \%$ rice husk may be used for making parts of automobiles. But these will not be suitable to work in moist environment. How ever it is recommended that the composite with $10 \%$ rice husk will be suitable for structural applications like packaging, interior decorations, body of washing machines and domestic appliances etc.

\section{Acknowledgement}

The authors wishes to express their heartfelt gratitude to the authorities of CIPET, Bhubaneswar to provide the facilities for conducting the required tests in their laboratories. Special thanks are also due to the HOD and staff of Mechanical Engineering Department of Indira Gandhi Institute of Technology, Sarang without whose help this work would not have been completed.

\section{Referances}

[1]. Sexena, M., Morchhale, R.K., and Ashokan. P. "Industrial Waste Reinforced Polymer Composites as a Potential Wood Substitute Material," Jou. of Composite Materials, Vol 3, 2008, pp. 367-384.

[2]. Harish, S., Michael, D.P., Bansely, A.,Lal. D. M. and Rajadurai, A."Mechanical Property Evaluation of Natural Fibre Coir Composites," Jou.of Material Sc., 2009, Vol 4, pp.44-49.

[3]. Singla, J. and Chawla,B. . "Mechanical Property of Epoxy Resin Fly Ash Composite," Journal of Minerals \& Materials Characterization \& Engineering, Vol. 9, 2010, pp.199-210.

[4]. Qiao, Jing., Schaaf, Kristin., Amirkhizi, Alireza V., Nasser, Sia Nemat. "Effect of Particle Size and Volume Fraction on Tensile Properties of Flyash Polyurea Composites," Behaviour and Mechanics of Multifunctional Materials and Composites, 2010, pp76441X 1-4. 
[5]. Syafri, Rahmadini., Ahmad, Ishak. \& Abdullah, Ibrahim., "Effect of Rice Husk Surface Modification by LENR on Mechanical Properties of NR/HDPE Reinforced Rice Husk Composite," Sains Malaysiana,Vol.7,2011,pp.749-756.

[6]. Rout, Arun.Kumar. ,Satapathy,Alok.,"Study on Mechanical and Tribo- performance of Rice-husk Filled Glass-Epoxy Hybrid Composites,"Proc. of 5th International and $26^{\text {th }}$ All India Manufacturing Technology-Design and Research Conference, IIT Guwahati, Assam , Vol.4,2012 pp131-141.

[7]. Subham, P. and Tiwari, S. K. "Effect of Fly Ash Concentration and its Surface Modification on Fiber Reinforced Epoxy Composite's Mechanical Properties,” Int. Jou. of Scientific \& Engineering Research, Vol.4, 2013,pp.1173-1180.

[8]. Raghavendra, G. , Acharya, S.K. , Pal, S.K. ,Ojha, S. "Mechanical Properties of Fly Ash Filler in Natural Fiber- Hybrid Epoxy Composites" Proc. of 7th ISFR 2013,pp.23-26.

[9]. Arpitha, G. R., Sanjay, M. R., Naik,L.L., Yogesha, B., "Mechanical Properties of Epoxy Based Hybrid Composites Reinforced with Sisal/SiC/Glass Fibers, International Journal of Engineering Research and General Science” Vol. 2, 2014, pp.398-405.

[10]. Islam, Md. Mahfujul. , Kabir, Humayun., Gafur, Md. Abdul. , Bhuiyan, Md. Mahbubur Rahman., Kabir, Md. Alamgir., Qadir, Md. Rakibul., Ahmed, Farid. " "Study on Physio- Mechanical Properties of Rice Husk Ash Polyester Resin Composite," International Letters of Chemistry, Physics and Astronomy, Vol. 53,2015,pp 95-105.

[11]. Vishnu, Manavendra,G. , "Experimental Investigation on Thermal Properties of Fly Ash Reinforced Epoxy Composite ," International Journal of Innovative Research in Science, Engineering and Technology, Vol. 5, Issue 12, December 2016.pp.2072320729

[12]. Mishra, Antaryami "Investigations of Mechanical Characteristics of Chicken Feather-Teak wood Dust Filled Epoxy Composites," International Journal of Engineering Research and Development, Volume 13, 2017, pp.1-9. 